\title{
RELATORIO DO ANNO 1925
}

Cumprindo o disposto na letra i) do art. 114 do decreto n. 11.530, de 18 de Março de 1915, letra $f$ ) do art. 199 do decreto n. ${ }^{\circ}$ 16.782-A, de 13 de Janeiro de 1925 e do n. $^{\circ}$ XVIII do art. 9. do Regimento Interno desta Faculdade, passo a fazer o relatorio minucioso de tudo quanto occorreu neste estabelecimento, a respeito da disciplina, ordem, serviço militar e observancia das leis e do orçamento, no anno lectivo de 1925.

Abertura dos trabalhos. - Na fórma do disposto no art. 74 do decr. n. ${ }^{\circ} 11.530$, de 18 de Março de 1915 e do art. 143 do Regimento Interno desta Faculdade, então em vigor, os trabalhos deste Instituto de ensino abriram-se no dia 2 de Março, celebrando a Congregação dos Professores nesse mesmo dia a sua primeira reunião, por ter sido domingo o dia $1 .^{\circ}$

Presença dos Professores. - Na primeira reunião da Congregação realizada a 2 de Março, foi verificado que se achavam promptos para os cursos os Professores Drs. Uladislau Herculano de Freitas, Antonio Amancio Pereira de Carvalho, Antonio Januario Pinto Ferraz, Manoel Pedro Villaboim, José Ulpiano Pinto e Souza, Candido Nazianzeno Nogueira da Motta, Reynaldo Porchat, Frederico Vergueiro Steidel, João Braz de Oliveira Arruda, Luiz Barbosa da Gama Cerqueira, Estevam de Araujo Almeida, Manoel Pacheco Prates, José Manoel de Azevedo Marques, Theophilo Benedicto de Souza Carvalho, José Joaquim Cardozo de Mello Neto, Francisco Antonio de Almeida Morato, e Octavio Mendes, e o substituto, na regencia de 
cadeira, Braz de Sousa Arruda, além dos substitutos que não regiam cadeiras, Dr. Jośé de Alcantara Machado d'Oliveira, Raphael Corrêa de Sampaio, José Augusto Cesar e Spencer Vampré.

Exame vestibular. - Na forma do disposto no art. 62 do Regimento Interno, a inscripção para o exame vestibular, instituido pelo art. 77 do decreto $\mathrm{n}^{\circ} 11.530$, de 1915, para a matricula no curso dẹsta Facudade, aberta a 2 de Janeiro e encerrada a 12 do mesmo mez, e reaberta a 7 de Março, de conformidade do art. 2..$^{\circ}$ do dec. 4.228, de 20 de Dezembro de 1921, e a resolução do Conselho Superior do Ensino, tomada em sessão de 23 de Fevereiro de 1922, foi encerrada a 16 desse mesmo mez, tendo concorrido á primeira inscripção dezesete (17) candidatos e á segunda, cincoenta e quatro (54). O exame iniciou-se com a prova escripta para os inscriptos na $1 .^{\mathrm{a}}$ epoca, no dia 27 de Janeiro, terminando no dia 29 seguinte; e, para os inscriptos na $2 .^{a}$ epoca, no dia 23 , tendo terminado no dia 30 de Março. $O$ resultado desse exames foi o seguinte: em Janeiro, approvados 11 , reprovados 2, inhabilitados na escripta, 3, não tendo comparecido á prova escripta 1 ; em Março, approvados 42, reprovados 3 e inhabilitados na escripta, 9, perfazendo o total de setenta e um (71). (Annexo respectivo).

A commissão julgadora desses exames foi constituida, na primeira epoca, pelos Professores desta Faculdade Drs. Candido Nazianzeno Nogueira da Motta, Frederico Vergueiro Steidel, Theophilo Benedicto de Souza Carvalho, Francisco Antonio de Almeida Morato, Manoel Pacheco Prates e Spencer Vampré; e na 2. ${ }^{a}$ epoca, pelos mesmos professoress, tendo o Dr. Raphael Corrêa de Sampaio substituido ao Dr. Candido Nazianzeno Nogueira da Motta, que participou não poder comparecer. 
Horario das aulas. - Pela Congregação, em sessão de 2 de Março, foi adoptado o Horario das aulas, constantes do annexo respectivo.

Programmas de ensino. - Adoptados pelos professores das cadeiras do curso, foi nomeada uma commissão composta dos Drs. José Ulpiano Pinto de Souza, José Manoel de Azevedo Marques, José Joaquim Cardozo de Mello Neto, a qual formulou seu parecer, opinando pela sua approvação, parecer esse que foi approvado na mesmá séssão de 2 de Março. Os programmas foram impressos e postos á venda na Thesouraria da Faculdade.

Designação de professores. - No decorrer do anno findo, foram designados: o Bacharel Waldemar Martins Ferreira, livre-docente, para reger a $10^{a}$ cadeira do 3 . anno, em substituição ao Dr. Octavio Mendes; o Dr. Spencer Vampré, substituto da l. secção, para reger a 3." cadeira do l. anno, em substituição ao Dr. Reynaldo Porchat, a $3 .^{a}$ cadeira do 2." anno, em substituição ao Dr. José Augusto Cesar, a 3." cadeira do 5. ${ }^{\circ}$ anno, em substituição ao Dr. Antonio Amancio Pereira de Carvalho e a 4. ${ }^{a}$ cadeira do 5. ${ }^{\circ}$ anno, em substituição ao Dr. Manoel Pedro Villaboim; o Dr. Braz de Sousa Arruda, substituto da 2. " secção, para reger a 2.' cadeira do 1 . anno, em substituição ao Dr. Uladislau Herculano de Freitas; o Dr. José Augusto Cesar, substituto da $3 .^{a}$ secção, para reger a 3 . $^{\prime}$ cadeira do 2. ${ }^{\circ}$ anno, em substituição ao Dr. José Ulpiano Pinto de Souza; o Dr. Raphael Corrêa de Sampaio, substituto da 4." secção, para reger a 2." cadeira do 4." anno, em substituição ao Dr. Luiz Barbosa da Gama Cerqueira, a $1 .{ }^{\text {a }}$ cadeira do $5 .^{\circ}$ anno, em substituição ao Dr. Estevam de Araujo Almeida, e a 2." cadeira do 5. anno, que ficou vaga, em substituição ao Dr. José Manoel de Azevedo Marques e o Dr. Frederico Vergueiro Steidel, cathe. 
dratico, para reger a $1 .^{a}$ cadeira do $3 .^{\circ}$ anno, em substituição ao Dr. Octavio Mendes.

Inscripção para exames da segunda epoca. - Para os exames da segunda epoca inscreveram-se cincoenta (50) alumnos, sendo: no $1 .^{\circ}$ anno 8 , no $2 .^{\circ} 8$, no $3 .^{\circ} 21$, no $4 .^{\circ} 12$ e no $5 .^{\circ} 1$. O resultado desses exames consta do annexo respectivo.

Inscripção de matricula. - Matricularam-se nos cinco annos do curso trezentos e seis (306) alumnos, sendo: no $1 .^{\circ}$ anno 59 , no $2 .^{\circ} 58$, no $3 .^{\circ} 66$, no $4 .^{\circ} 68$ e no $5 .^{\circ} 55$.

Transferencia de matricula. - Durante o periodo das ferias, somente dois alumnos requereram guia de transferencia, sendo ambos do $3 .^{\circ}$ anno, um para a Faculdade de Direito da Universidade do Rio de Janeiro e outro para a Faculdade Livre de Direito do Estado do Pará.

Licenças. - Durante o anno findo, estiveram no gozo de licença: o Dr. José Ulpiano Pinto de Souza, cathedratico da $3 .^{a}$ cadeira do $2 .^{\circ}$ anno, de 1 a 26 de Maio; o Dr. Reynaldo Porchat, cathedratico da $3 .^{\mathrm{a}}$ cadeira do $10^{\circ}$ anno, de 26 de Maio a 24i de Junho; o Dr. Luiz Barbosa da Gama Cerqueira, cathedratico da $2 .^{\text {a }}$ cadeira do $4 .^{\circ}$ anno, de 22 de Abril a 2 de Maio; o Dr. Estevam de Araujo Almeida, cathedratico da $1 .^{\text {a }}$ cadeira do $5 .^{\circ}$ anno, de 26 de Agosto a 4. de Setembro; o Dr. José Manoel de Azevedo Marques, cathedratico da $2 .^{\text {a }}$ cadeira do $5 .^{\circ}$ anno, de $1 .^{\circ}$ de Agosto a 30 de Setembro, considerado licenciado, nos termos do disposto no art. $3 .^{\circ} \oint 5 .^{\circ}$ do decreto $n .^{\circ} 11.447$, de 20 de Janeiro de 1915, visto ter requerido a sua aposentadoria; o Dr. Octavio Mendes, cathedratico da $1 .^{a}$ cadeira do $3 .^{\circ}$ anno, de 3 de Abril a 31 de Dezembro; e o Dr. José Augusto Cesar, cathedratico da $3 .^{\text {a }}$ cadeira do $2 .^{\circ}$ anno, de 5 Outubro a 21 de Dezembro.

Serviço publico. - Durante o anno findo, estiveram ausentes da Faculdade, por motivo de serviço publico: o Dr. 
Uladislau Herculano de Freitas, como representante desta Faculdade, no Conselho Superior do Ensino, de 1. de Fevereiro a 11 de Março, e de $1 .^{\circ}$ de Maio a 31 de Dezembro por estar com assento no Congresso Nacional, como Deputado por São Paulo; o Dr. Manoel Pedro Villaboim, cathedratico da $4 .^{a}$ cadeira do $5 .^{\circ}$ anno, de $1 .^{\circ}$ de Maio a 31 de Dezembro, por estar com assento no Congresso Nacional. como Deputado por São Paulo; e o Dr. Reynaldo Porchat, cathedratico da 3." cadeira do 1. anno, como representante desta Faculdade, no Conselho Superior do Ensino, de $1 .^{\circ}$ de Fevereiro a 14 de Março.

Substituições. - No correr do anno findo, o Dr. Antonio Amancio Pereira de Carvalho, professor cathedratico mais antigo e vice-Director, na fórma da lei, substituiu ao Dr. Uladislau Herculano de Freitas, no exercicio do cargo de Director, de $1 .^{\circ}$ de Fevereiro a 11 de Março e de $1 .^{\circ}$ de Maio a 31 de Dezembro; o Dr. Waldemar Martins Ferreira, livre-docente de Direito Commercial, de $1.0^{\circ}$ de Junho a 31 de Dezembro, regeu a $1 .^{a}$ cadeira do $3 .^{\circ}$ anno, em substituição ao Dr. Octavio Mendes; o Dr. Spencer Vampré, substituto da $1 .^{a}$ secção, depois cathedratico da $3 .^{a}$ cadeira do $1 .{ }^{\circ}$ anno, de 4 de Maio a 31 de Dezembro, regeu a $4 .^{i}$ cadeira do 5. anno, em substitução ao Dr. Manoel Pedro Villaboim, de 26 de Maio a 24 de Junho e de $1 .^{\circ}$ de Outubro a 23 de Novembro, a 3." cadeira do 1." anno, que ficou vaga, a $1 .^{\circ}$ de Outubro, em substituição ao Dr. Reynaldo Porchat, que antes esteve no gozo de licença e depois no gozo da sua disponibilidade; de 13 de Agosto a 30 de Setembro, a $3 .^{a}$ cadeira do $5 .^{\circ}$ anno, em substituição ao Dr. Antonio Amancio Pereira de Carvalho, que foi posto em disponibilidade, e de 5 de Outubro a 30 de Novembro, a $3 . "$ cadeira do 2. anno, em substituição ao Dr. José Augusto Cesar; o Dr. Braz de Sousa Arruda, substituto da 2. seç̧ão e depois cathedratico da $1 .^{a}$ cadeira do 2 . anno, de 4 de 
Maio a 31 de Dezembro, regeu a 2.' cadeira do $1 .^{\circ}$ anno, em substituiu ao Dr. Uladislau Herculano de Freitas; o Dr. José Augusto Cesar, substituto da 3. ${ }^{a}$ secção e depois cathedratico da $3 .^{2}$ cadeira do 2 . anno, que ficou vaga a $27 \mathrm{de}$ Maio, em substituição ao Dr. José Ulpiano Pinto de Souza, que antes esteve no gozo de licença e depois no gozo de disponibilidade; o Dr. Raphael Corrêa de Sampaio, substituto da 4. ${ }^{\mathrm{a}}$ secção e depois cathedratico de Direito Penal Militar e respectivo Processo, de 22 de Abril a 13 de Maio, regeu a $2 .^{a}$ cadeira do $4 .^{\circ}$ anno, em substituição ao Dr. Luiz Barbosa da Gama Cerqueira; de 26 de Agosto a 4 de Setembro, regeu a $1 .^{a}$ cadeira do $5 .^{\circ}$ anno, em substituição ao Dr. Estevam de Araujo Almeida, e de $1 .^{\circ}$ de Agosto a 31 de Dezembro, regeu a 2.' cadeira do 5.․ anno, em substituição ao Dr. José Manoel de Azevedo Marques, que antes foi considerado licenciado e depois aposentado; e o Dr. Frederico Vergueiro Steidel, cathedratico da $1 .^{a}$ cadeira do 4. ${ }^{\circ}$ anno. de 3 de Abril a 11 de Maio, regeu a $1 .^{a}$ cadeira do $3 .^{\circ}$ anno, em substituição ao Dr. Octavio Mendes.

Reforma do ensino supérior. - Publicado o Decreto n. 16.782-A, de 13 de Janeiro de 1925, a Congregação dos professores desta Faculdade reuniu-se no dia 20 de Abril, para tomar conhecimento das disposições desse decreto, que reformou o ensino secundario e superior da Republica e adoptar as providencias necessarias para esse effeito, e, nẹssa reunião, foi resolvido que esta Faculdade, adoptando a referida reforma, desde logo, désse cumprimento ao disposto nos artigos 14, 57, 195, 196 e 296 do referido decreto 16.782-A.

Representante da Faculdade no, Conselho Superior do Ensino. - Na sessão da Congregação, realizada a 20 de Abril, foi eleito o Dr. Reynaldo Porchat, para representar esta Faculdade no Conselho Superior do Ensino. 
Commissões auxiliares do Director.- Na sessão de 20 de Abril, já referida, foram eleitos os Drs. João Braz de Oliveira Arruda, José Joaquim Cardozo de Mello Neto e Spencer Vampré, para a commissão de ensino; os Drs. Antonio Amancio Pereira de Carvalho, Antonio Januario Pinto Ferraz e Theophilo Benedicto de Souza Carvalho, para a commissão de docencia, e os Drs. José Manoel de Azevedo Marques, Spencer Vampré e Braz de Sousa Arruda, para a commissão de redacção e publicações.

Regimento Interno. - Na mesma sessão de 20 de Abril, foram eleitos os Drs. Estevam de Araujo Almeida Frederico Vergueiro Steidel e Francisco Antonio de Almeida Morato, para, em commissão elaborarem o novo Regimento Interno desta Faculdade, de accordo com as disposições da referida reforma de ensino. Essa commissão apresentou o seu trabalho, que foi submettido a diversas discussões em sessões da Congregação, sendo o projecto desse Regimento interno, depois de approvado pela Congregação, com as emendas suggeridas pelos demais professores, enviado ao Exmo. Snr. Dr. Ministro da Justiça e Negocios interiores para a sua approvação, com o officio $\mathrm{n}$. 23 , de 10 de Julho, por intermedio do Departamento Nacional do Ensino.

Livres-docentes, nomeação e posse.- Foram nomeados para esta Faculdade: o Bacharel Waldemar Martins Ferreira, habilitado no anno 1920, em concurso ao logar de substituto da 6. ${ }^{\mathrm{a}}$ secção (Direito Commercial), para o logar de livre-docente de Direito Commercial, por Portaria desta Directoria, de 6 de Maio do anno findo, tendo tomado posse no dia 8 desse mesmo mez; o Bacharel Manoel Francisco Pinto Pereira, habilitado no anno de 1920, em concurso ao logar de substituto da 2." seç̧ão (Direito Publico e Constitucional e Direito Internacional Publico e Privado) para o logar de livre-docente de Di- 
reito Internacional Publico e Privado, por Portaria desta Directoria, de 4 de Outubro de 1925, tendo o mesmo tomado posse nessa mesma data; e o Bacharel Antonio de Sampaio Doria, habilitado em 1920, em concurso ao logar de substituto da $2 .^{\mathrm{a}}$ secção (Direito Publico e Constitucional e Direito Internacional Publico e Privado), para o logar de livre-docente de Direito Publico e Constitucional e Direito Internacional Publico e Privado, por Portaria desta Directoria, de 18 de Novembro de 1925, tendo tomado possé nessa mesma data.

Livres-docentes, revalidação de titulos. - Com a publicação do Decreto n..$^{\circ}$ 16.782-A, de 13 de Janeiro de 1925, foram revalidados, por dez annos, os titulos de Bachareis Laurentino Antonio Moreira de A'zevedo, livre: docente da antiga $1 .^{a}$ secção e do Bacharel Gabriel José Rodrigues de Rezende Filho, livre-docente da antiga $7 .^{\mathrm{a}}$ seçãa, conforme requereram, de accordo com os arts. 175 e 287. do referido decreto n. 16.782-A, de 1925.

Inscripção para defeza de theses. - No dia 15 de Abril, inscreveu-se para a defeza de theses, como candidato ao doutoramento, o Bacharel Raul Apocalypse. As theses apresentadas foram approvadas pela Congregação dos Professores, sendo designado o dia 29 de Março de de 1926, para a realização da referida defeza de theses.

Disponibilidade. - Nos termos do art. 188 do decr. 16.782-A, de 1925, citado, foram postos em disponibilidade, conforme requereram: o Dr. José Ulpiano Pinto de Souza, então cathedratico do Direito Civil por decreto de 27 de Maio, tendo começado a gozar das vantagens da disponibilidade, no dia 8 de Junho; o Dr. Antonio Amancio Pereira de Carvalho, então cathedratico de Medicina Publica, por decreto de 15 de Julho, tendo começado a gozar das vantagens da disponibilidade, no dia 2 de Agosto, e o Dr. Reynaldo Porchat, então caihedratico de Direito Romano, por decreto de 29 de Julho, 
tendo começado a gozar das vantagens da disponibilidade. no dia $1 .^{\circ}$ de Outubro.

Aposentadoria. - Por deçreto de 16 de Setembro. aposentado o Dr. José Manoel de Azevedo Marques, entãc cathedratico da $2 .^{\text {a }}$ cadeira do $5 .^{\circ}$ anno(Theoria e Pratica do Processo Criminal), tendo o mesmo comergado a gozar das vantagens de aposentadoria, no dia $1 .{ }^{\circ}$ de Outubro seguinte.

Vagas de cadeiras. - Com as disponibilidades dos Drs. José Ulpiano Pinto de Souza, Antonio Amancio Pereira de Carvalho e Reynaldo Porchat, e com a aposentadoria do Dr. José Manoel de Azevedo Marques, ficaram vagas, respectivamente, as cadeiras seguintes: $3 . "$ do $2 . "$ anno (Direito Civil); $3 .^{a}$ do $5 .^{\circ}$ anno actual (Medicina Publica); $3 .^{.}$do $1 .^{\circ}$ anno actual (Direito Romano); e 2. do 5. anno actual (Theoria e Pratica do Processo Criminal), todas as quatro que se comprehendiam no curso juridico, segundo o decreto 11.530 , de 18 de Março de 1915.

Nomeações e posses de cathedraticos. -- Durante o anno findo, foram nomeados: o Dr. Raphael Corrêa de Sampaio, então substituto da $4 .^{a}$ secção, para o logar dr cathedratico de Direito Penal Militar e respectivo Processo (cadeira creada pelo decr. 16.782-A, de 1915), por decr. de 6 de Maio, tendo o mesmo tomado posse e entrado em exercicio, no dia 14 desse mesmo mez; o Dr. Braz de Sousa Arruda, então substituto da 2." secção, para o logar de cathedratico de Direito Publico Internacional, por decr. de 6 de Maio, tendo tomado posse e entrado em exercicio no dia 14 desse mesmo mez; o Dr. José Augusto Cesar, então substituto da $3 .^{a}$ secção, para o logar de cathedratico de Direito Civil, por decr. de 15 de Julho, tendo o mesmo tomado posse e entrado em exercicio, no dia 3 de Agosto seguinte; o Dr. José de Alcantara Machado d'Oliveira, então substituto da 8." secção, para o logar de cathedra- 
tico de Medicina Publica, por decr. de 19 de Agosto, tendo tomado posse e entrado em exercicio, no dia 18 de Setembro seguinte, e o Dr. Spençer Vampré, então substituto da 1. ${ }^{2}$ secção, para o logar de cathedratico de Direito Romano, por decr. de 11 de Novembro, tendo o mesmo tomado posse e entrado em exercicio, no dia 24 desse mesmo mez.

Inscripção para exames da 1 . $^{\mathrm{a}}$ epoca. - Para os exames da primeira epoca, inscreveram-se 258 alumnos, sendo no $1 .^{\circ}$ anno 50 , no $2 .^{\circ} 51$, no $3 .^{\circ} 53$, no $4 .^{\circ} 49$, e no $5 .^{\circ} 55$. 0 resultado desses exames, consta do annexo respectivo.

Collação de grau. - Durante o anno findo, foi collado o grau de Bacharel em Sciencias Juridicas e Sociaes, a 50 Bacharelandos, dos quaes um concluiu o curso em 1924, um na 2. epoca, de 1925, e os restantes 48 o concluiram na 1." epoca de 1925 findo. Desses 50 Bachareis são naturaes; do Estado de São Paulo, 41; de Minas Geraes, 3; da Bahia, 2; de Santa Catharina, 1; do Rio Grande do Sul, 1; de Alagôas, 1 e de Pernambuco, 1.

Cartas de Bacharel. - No correr do anno findo, foram expedidas 88 Cartas de Bacharel a igual numero de Bachareis formados por esta Faculdade, em Sciencias Juridicas e Sôciaes. Desses 88 Bachareis, são naturaes: do Estado de São Paulo, 70; de Minas Geraes, 5; da Cidade do Rio de Janeiro, 2; do Estado da Bahia, 2; do de Pernambuco, 2; do de Santa Catharina,1; do de Sergipe, 1; do de Amazonas, 1; do de Alagôas, 1; do de Paraná, 1; do de Rio Grande do Sul, 1, e da Republica de Portugal, 1.

Serviço Militar. -- De conformidade com a informação prestada pelo respectivo Instructor Militar, durante o anno findo, frequentaram a instrucção militar apenas 9 alumnos destä Faculdade, os quaes, tendo prestado exame, foram approvados. 
Sessões da Congregação. - No correr do anno findo, a Congregação dos professores celebrou onze (11) sessĩes: nas quaes foram tratados diversos assumptos.

Procedimento dos alumnos. - $\mathrm{O}$ procedimento dos alumnos no correr do anno lectivo findo, foi bom, nada tendo occorrido digno de menção.

Bibliotheca. - A Bibliotheca desta Faculdade, durante o anno findo, foi frequentada por 4.848 pe:sôas, que consultaram 1.705 obras, em 3.359 volumes, sendo, em portuguez, 1.150; em francez, 282; em latim, 67; em italiano, 111; inglez, 30; e em allemão, 2, estando no numero dos consulentes incluidas 2.066 pessôas que leram jornaes e revistas. Os empregados da Bibliotheca bem cumpriram os seus deveres.

Thesouraria. - O balanço demonstrativo da Thesouraria desta Faculdade, constante do annexo respectivo, fechado a 2 de Janeiro de 1926, accusa que da receita e despeza ha um saldo de 727:212\$400 (setecentos e vinte sete contos duzentos e doze mil quatrocentos réis), assim distribuido: no Banco do Commercio e Industria 5:950\$400 (cinco contos novencentos e cincoenta mil quatrocentos réis); no Banco do Brazil 35:262\$000 (trinta e cinco contos duzentos e sessenta e dois mil réis); e 686:000\$000 (seiscentos e oitenta e seis contos de réis), importancia de 686 apolices da União, do valor de l:000\$000 (um conto de réis), cada uma, e ao juro de cinco por cento $(5 \%)$ ao anno.

0 saldo apurado em 1925, foi de 742:557\$600 (setecentos e quarenta e dois contos quinhentos e cincoenta e sete mil seiscentos réis), havendo, portanto, uma differença a menos de 15:345\$200 (quinze contos trezentos e quarenta e cinco mil duzentos réis). 0 Thesoureiro bem cumpriu os seus deveres. 
Secretaria. - Os serviços da Secretaria estiveran sempre em dia, tendo os empregados bem cumprido os seus deveres.

Secretaria da Faculdade de Direito de São Pauls, em 25 de Fevereiro de 1926.

O Director:

Dr. Uladislau Herculano de Freitas. 